\title{
Spray Characteristics and Wall Impingement of Diesel-CNG Dual Fuel Jet Using Schlieren Imaging Technique
}

\author{
Mhadi A. Ismael, M. R. Heikal, and M. B. Bahroom
}

\begin{abstract}
Natural gas for direct-injection (DI) compression ignition (CI) engines is considered to be the best optimized method due to its high volumetric efficiency, high thermal efficiency and low emissions. However, CNG has the penalty of high auto-ignition temperature and lower cetane number. An effective way to use CNG in CI engines is to inject the CNG with a pilot of diesel fuel for ignition purposes. This research is an experimental investigation of the direct injection of CNG jet, diesel spray and combination of fuels (i.e. natural gas with pilot of diesel fuel) in a constant volume chamber using an optical method. The jets were created using two parallel injectors. A low pressure CNG injector (electronic) was used at different injection pressures ranging from 14 bar to 18 bar, while a diesel sprayed injector was used for a high pressure common rail injector ranging from 500 to 700 bar. The Schlieren technique was used for flow visualization and a high speed video camera was used for image acquisition. Series of images of a jet at different time intervals from the beginning of the injection were taken to determine the macroscopic characteristics such as jet penetration rate, jet cone angle and jet tip velocity. The jet radial and height travel along the wall under different injection pressures and temperatures were also measured. Image processing software was developed and used for the analysis.
\end{abstract}

Index Terms-CNG, Diesel-CNG dual fuel, spray wall impingement, schlieren, image processing.

\section{INTRODUCTION}

In recent years, natural gas is being used increasingly in internal combustion diesel engines due to the lower costs compared to petroleum [1]. There are different principal methods for NG to be used in compression ignition engines: the first one, the natural gas is injected into the inlet manifold, mixes naturally with the air and forms a fully pre-mixed fuel-air mixture in the combustion chamber. Thus a mixture of gas and air is compressed during the compression stroke and before the end of the stroke; a pilot quantity of diesel fuel is injected to initiate combustion [2]. This kind of operating condition produces a none-uniform mixture distribution of

Manuscript received November 15, 2014; revised March 25, 2015. This work was supported in part by the UTP (University Teknologi PETRONAS) Department of Mechanical Engineering under Grant URF (Spray Characteristics and Wall Impingement of Diesel-CNG Dual Fuel Jet Using Schlieren Imaging Technique)

Mhadi A. Ismael is with the Bahri University, Malaysia (e-mail: xmhadosx@yahoo.com).

M. R. Heikal is with the Universiti Teknologi Petronas, $\mathrm{He}$ is now with the Department of Mechanical, Bandar Seri Iskandar, 31750 Tronoh, Malaysia (e-mail: morgan.heikal@ petronas.com.my).

M. B. Bahroom is with the Mechnical Engineering Department, University Teknologi Petronas, Boulder, Bandar Seri Iskandar, 31750 Tronoh, Malaysia (e-mail: masrib@petronas.com.my). the natural gas inside the engine. In addition, this system does not favor the two-stroke engine due to the escape of some of the natural gas fuel into the exhaust [3]. The second method of using natural gas in diesel engines is the direct injection of natural gas near to the diesel fuel spray into the combustion chamber [4]. Thus a full stratification of the fuel-air mixture can be obtained with good flammability over the entire load range.

Recently, successful operation has been demonstrated by applying this method using a prototype co-injector [5], resulting in diesel-gas two phase mixtures which were then injected into the chamber. The authors recommended that the jet penetration should be imaged and characterized to further understand the complex two-phase flow phenomena. It appears that direct injection of natural gas with diesel pilot ignition is one of the most promising ways of meeting the energy crises and emissions regulation, analogous to the benefits provided by a common rail high pressure direct injection engine.

Actually, the development of high performance natural gas DIEs is unclear as the macroscopic characteristics of the diesel-CNG dual fuel jet which differs considerably from that of diesel fueled compression ignition $(\mathrm{CI})$ and spark ignition (SI) engines. In diesel-CNG dual fuel engine, the performance of the engine is influence significantly by the quality of the diesel fuel sprays and CNG jet propagation. Those characteristics can be classified into two basic categories: Macroscopic and microscopic. The first one, which involves spray tip penetration, spray cone-angle, and their derivatives and the second, involves droplet velocity, droplet size, size distribution and air fuel ratio [6]. Improvement of the diesel-CNG dual fuel jet characteristics such as jet tip penetration, jet cone angle and jet velocity in turn determine the diesel-CNG dual fuel combustion process and the associated formation of pollutants. In addition, these characteristics not only aim to improve the engine efficiency, but also assist the understanding of parameters used to judge fuel spray performance [7]. For example, the spray penetration length must neither be too long nor short in a combustion chamber. If too long, impingement could occur resulting in wetting of cylinder walls and/or piston crown [8]. Spray-wall impingement can be characterized into radial penetration along the wall and jet height. Improvement of those characteristics leads to enhance the mixture formation as well as the combustion process. The present work investigates the jet propagation of jets created by $\mathrm{CNG}$ and diesel injectors with aid of flow visualization. Based on the previous studies, it is well known that the injection strategy and the atomization play an important role for the diesel 
spray, and the mixture formation is largely dependent upon the droplet distribution and evaporation [9]. In contrast with diesel spray, natural gas does not have droplets and evaporation at all [10]. Besides the researches on the diesel fuel spray, many studies on high pressure gas jet have been conducted using different optical diagnostic techniques [11], 12] For example, gas jet characteristics at injection pressure 50 bar to 80 bar in a bomb was visualized and analyzed using planar laser-induced fluorescence (PLIF) technique were studied by [13]. While other studies using Schlieren technique to visualize natural gas in chambers [14]. However, high injection pressures of the gas require high performance injectors and associated with high energy consumption in the production of such high pressures. One of the objectives of this study is to examine the effect of low gas injection pressure combined with a common rail diesel injection pressure on the characteristics of the jet and jet-wall impingement.

\section{EXPERIMENTAL METHODS}

\section{A. Experimental Test Rig}

There were three major objectives in setting up the experimental rig: to capture the fuel spray in a constant-volume chamber as far as the fuel supply, to vary the injectors-wall distance and to be able to use different injection pressures. This allowed using two injectors (diesel and $\mathrm{CNG}$ ) as those co-injectors which are employed in the performance testing in the engines [8], [15]. Generally, spray research has been performed in a number of different test rigs: special research engines, high pressure and high temperature bombs, flow rigs and constant volume chambers. A constant volume test rig was considered as the best option for fundamental research as it combined good optical access, large observation areas and good control of scavenging before injection. A chamber, $100 \mathrm{~mm}$ high and $86 \mathrm{~mm}$ wide (similar to the stroke \& bore of a CNG engine in the UTP automotive lab), was designed and built to allow for optical analysis of both the jets and wall impingement. The bottom plate of the test rig was made from aluminum (piston material) with a thermocouple inserted in it for temperature measurement. Different methods were used in previous studies for achieving representative temperature conditions in the rig e.g. some used direct heating of the walls (bottom) of the test rig [16], while others used an electric heater inside the plate. In this study, a controlled electric heater was used to heat the bottom plate. A common rail, electronically controlled injector system was used to generate and induce the high injection pressure sprays into the chamber. This injection system provided flexibility in controlling the injection timing, injection duration and the rail pressure. The fuel injection equipment included: an electric motor, a control unit, a high pressure fuel pump, a high pressure delivery pipe, a common rail, a regulator valve, a pressure gage, an injector driver and an injector. Fig. 1 shows a schematic of the connections between these components. The fuel pump powered by an electric motor (the speed of motor was $1420 \mathrm{rev} / \mathrm{min}$ ) which was controlled through an electronic control unit (ECU). To ensure stable set rail pressure, a pressure regulator valve and pressure gage were used. An injector driver circuit was built and used to control the opening and closing of the injector valve by which we were able to control the injection timing and injection duration which was built into a lab VIEW program. In order to study a single fuel spray, different researchers modified their injectors from different numbers of holes to study a single-hole nozzle [3]-[5], [9]. D. A. Kennaird et al. [17] in their study of multi-hole and single hole injectors spray penetration characteristics found that, single-hole injector was valid to characterize spray. Therefore, the injector used in this study was modified from 6 to a single-hole $(0.3 \mathrm{~mm}$ diameter) to characterize the axial spray penetration. The chosen injection pressures in this study were: 500, 600 and 700 bar.

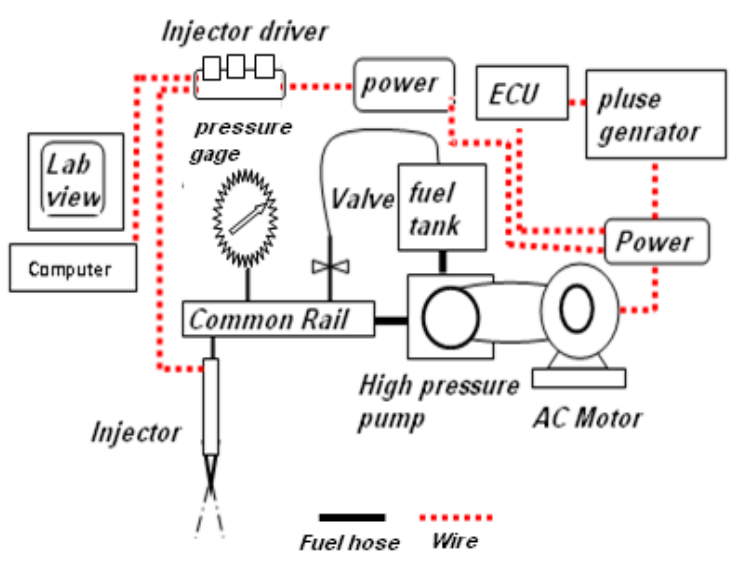

Fig. 1. Diesel fuel injection system.

\section{B. Experimental Procedure}

The experimental conditions are listed in Table 1. The natural gas found in Malaysia which consists mainly of methane, ethane and propane was used in this project. The CNG injection system is shown in Fig. 2.

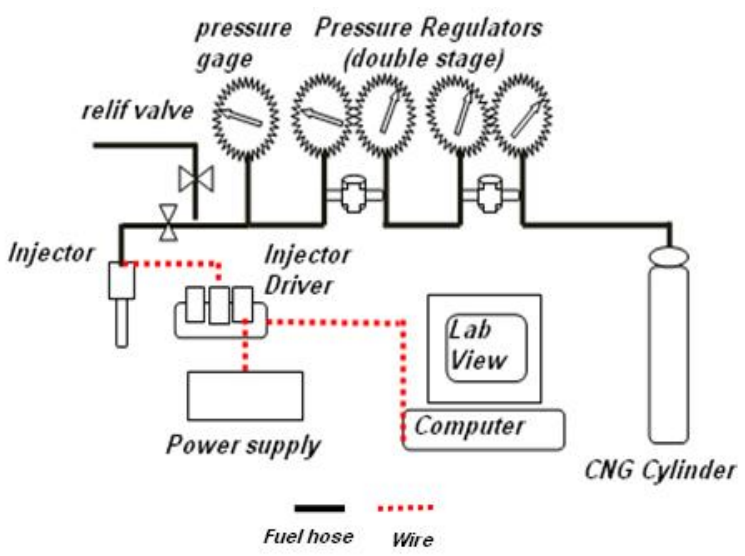

Fig. 2. CNG fuel injection system.

A National Instrument driver and a power supply (12V) were used to drive the injectors (diesel and CNG) with injection duration (solenoid valve opening) $5 \mathrm{~ms}$. The images were captured using the Schlieren system which consisted of a lamp, two concave mirrors, a knife edge and a high speed video camera (Phorton, FASTCAM-APX) operated at a speed of 8,000 frames per second. 
TABLE I: EPERIMENTAL CONDITIONS

\begin{tabular}{lll}
\hline \hline FUEL & CNG & DIESEL \\
\hline $\begin{array}{l}\text { Injection pressure (bar) } \\
\text { Injection duration (ms) }\end{array}$ & 5 & 500,600 and 700 \\
Ambient pressure (bar) & 1 & 5 \\
Injector wall distance & 80,60 and 40 & 80,60 and 40 \\
$(\mathrm{~mm})$ & & \\
\hline \hline
\end{tabular}

\section{Diesel Fuel Measurement}

The quantity diesel fuel emerging from a single hole injector was calculated based on the pressure difference between the fuel supplied pressure and the ambient pressure in the chamber. As the injected fuel quantity per unit time is a linear function of pressure [18], a quantitative estimate of a single fuel injection as given by Eq. (1)

$$
\mathrm{Q}=\frac{A}{a p} \int_{t 0}^{t} P d t
$$

where: $Q$ is the injected fuel $(\mathrm{g} / \mathrm{s}), P=$ injection pressure (bar), $A=$ cross sectional area of the nozzle in $\left(\mathrm{m}^{2}\right), a=$ is velocity of sound in the fuel $(\mathrm{m} / \mathrm{s}), p=$ density of the fuel $(\mathrm{kg} / \mathrm{m} 3), \mathrm{t}=$ time at start of injection $(\mathrm{ms})$ and $=$ time at the end of injection (ms).

\section{Diesel Spray Characteristic Calculations}

Beside the experimental studies, many theoretical and empirical correlations were recommended for the predictions of the diesel spray penetration and the spray velocity. Several correlations have been suggested to determine the spray penetration. When the spray is first injected into the chamber, the initial velocity of the spray tip is much larger than the surrounding air. According to Hiroyasu and Arai [19] at this zone the penetration is described by an expression proportional to time.

$$
\begin{aligned}
& 0<t<t_{b} \quad S(t)=0.39 \sqrt{\frac{2 \Delta P}{\rho_{f}}} t \\
& t>t_{b} \quad S=2.95\left(\frac{\Delta P}{\rho_{g}}\right)^{0.5}\left(t d_{o}\right)^{0.5}
\end{aligned}
$$

where $t_{b}=$ break up time given by $t_{b}=\frac{28.65 \rho_{f} d_{o}}{\left(\rho_{g} \Delta P\right)^{0.5}}, S=$ Spray penetration, $\Delta P=$ pressure drop across the nozzle, $\rho_{f}=$ fuel density, $\rho_{g}=$ gas density, $t=$ time and $d_{o}=$ nozzle diameter.

While Dents [20] developed equation based on the gas jets theory, where spray penetration depends on the gas density and temperature as following:

$$
S=3.07\left(\sqrt{\frac{\Delta P}{\rho_{g}}} \times t d_{o}\right)^{0.5}\left(\frac{294}{T_{g}}\right)^{1 / 4}
$$

where $T_{g}=$ ambient gas temperature.

Spray tip velocities are considered to be dependent upon the injection pressure and the ambient pressure according to Hiroyasu et al. [21] as follows:

$$
\begin{aligned}
& U_{s}(t)=\frac{3}{2}\left(\frac{\rho_{f}}{\rho_{g}}\right)^{0.25}\left(\frac{\rho_{g}{ }^{1 / 3}}{12 \rho_{f}}\right)^{0.5} t^{0.5} 0<t<t_{\text {break }} \\
& U_{s}(t)=2.95\left(\frac{\Delta P}{\rho_{g}}\right)^{0.25}\left(\frac{\left(C_{f}\right)^{z} d}{t}\right)^{0.5} t \geq t_{\text {break }}
\end{aligned}
$$

where $C_{f}=\frac{d_{i}}{d_{o}}$ and $\mathrm{Z}$ is the power of conicity parameter, equals to $(-1)$ for convergent nozzles, (+1) for divergent nozzles and $(0)$ for straight nozzles.

\section{RESULTS AND DISCUSSION}

\section{A. Spray Tip Penetration Measurements}

Fig. 3 shows the development of the $\mathrm{CNG}$ jet created using $\mathrm{CNG}$ injector at 18 bar injection pressure and $80 \mathrm{~mm}$ injector to wall distance. The images were obtained using a high speed video camera trigged at the start of injection. The start of injection (SOI) is defined as the moment of the solenoid valve closure in the electronic diesel injector as in a common rail diesel injection system. It is different from the starting of the jet (SOJ), which is defined here as the first visible appearance of the jet emerging from the nozzle.

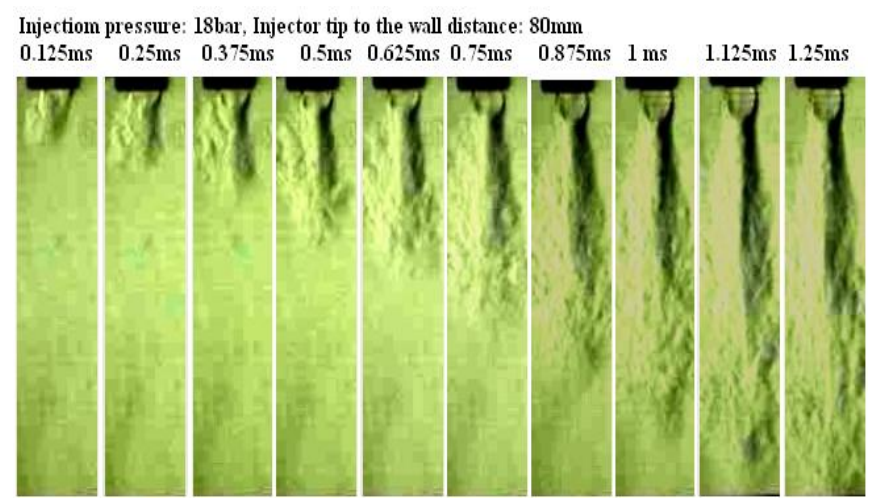

Fig. 3. Schlieren images of jet pattern of $\mathrm{CNG}$ at $18 \mathrm{bar}$ injection pressure and $80 \mathrm{~mm}$ injector to the wall distance.

In order to understand the development of the $\mathrm{CNG}$ jet, the jet pattern was divided into two regions: upstream region and downstream region. The first one starts from 0.125 to $0.5 \mathrm{~ms}$, while the later one starts from 0.625 to $1.125 \mathrm{~ms}$. At the upstream region, the development of the gas jet structure exhibited a wider jet cone angle which was thought to be due to low momentum of the gas jet as the injectors opened. This lower gas jet momentum also leads to a lower initial rate of jet tip penetration. As time elapsed (at downstream region), the rate of jet tip penetration increased. It was also noticed that the concentration distribution of the gas at the upstream region became lower in the last images as compared to the 
first images. The main mechanism for a free jet movement was explained by [22] who divided the jet into two main regions, namely the development region which is continued with a constant mean velocity up to the end of the jet potential core; and the fully developed region which began from the end of the core region. The edge of the jet was not straight because of a turbulent mixing process and entrainment of the flow from the still ambient air. However, a high fluctuation region was observed at the initial stages of the jet tip as it could be easily influenced by the surrounding air.

\section{B. Effect of Injection Pressure on the CNG Jet Penetration}

Fig. 4 shows the Schlieren images of the CNG jet under both ambient and different injection pressures $(18,16$, and 14 bar), the time intervals from $0.25 \mathrm{~ms}$ to $1.25 \mathrm{~ms}$ at increments of $0.25 \mathrm{~ms}$. As shown in the jet images, the injection pressure had a large influence on the jet structure as expected [10], [23], [24]. However, with increased of the injection pressures the delivery time was reduced. It can be said that the high injection pressure had a strong influence on the fuel delivery time as shown in the Fig. 4. (at $0.75 \mathrm{~ms}$ ). At the upstream region, the discrepancy of the penetration was quite small between their different injection pressures $(18,16$, and 14 bar), but this differences became more significant as time elapsed. This phenomenon was thought to be caused by the high flow rate leading to a high momentum of the CNG jet. In other words, the $\mathrm{CNG}$ jet became strong enough to overcome the resistance of ambient air. Furthermore, it was also noticed that the difference in the jet tip penetration between 18 bar and 16 bar were small in comparison with the differences between 16 bar and 14 bar as shown in Fig. 4. Based on this trend, it can be reasoned that, at 18 bar and 16 bar the jet momentum became strong to overcome the resistance of air medium than that of 14 bar. It was also noticed that the lower injection pressure (14 bar) not only lead to short tip penetration, but also resulted in higher concentration region in the center of the jet. The main reason was thought to be again the lower injection pressure leads to lower air-entrainment between the $\mathrm{CNG}$ fuel and the air. This resulted in less mixing. The main mechanism for air-entrainment into the flow can be seen in reference [22].

\section{Spray Tip Penetration Measurements}

Fig. 5 represents the spray evaluation process of the diesel and the diesel-CNG dual-fuel ranging from $0.125 \mathrm{~ms}$ to 0.75 $\mathrm{ms}$ after the start of injection. In order to compare the images of the diesel spray (single fuel) and diesel-CNG dual fuel jets, the process of the same threshold levels were used to distinguish the spray edges from the background, since the quality of images remained the same during the test runs. Here the spray development was divided into two regions: upstream region (for diesel fuel start from 0.125 to $0.625 \mathrm{~ms}$ ), while for diesel-CNG start from 0.125 to $0.5 \mathrm{~ms}$ and the rest was considered as downstream region. The spray tip penetration rate for both fuels increased with elapsed time. It can be seen that, most of the upstream region of the spray did not reach its fully developed shape which was in agreement with previous study of Taşkiran and Ergenman [25].

\section{Temperature Effects}

Before the experiment started, the temperature distribution inside the rig was measured and showed that there was a moderate gradient from bottom to top. When the bottom plate was heated up to $500 \mathrm{~K}$, the temperature variations were 72 , 64, 60 and $54 \mathrm{~K}$ at 20, 40, 60 and $80 \mathrm{~mm}$ from the bottom plate respectively. The ambient temperature inside the chamber was calculated from the average values of the temperature variation.

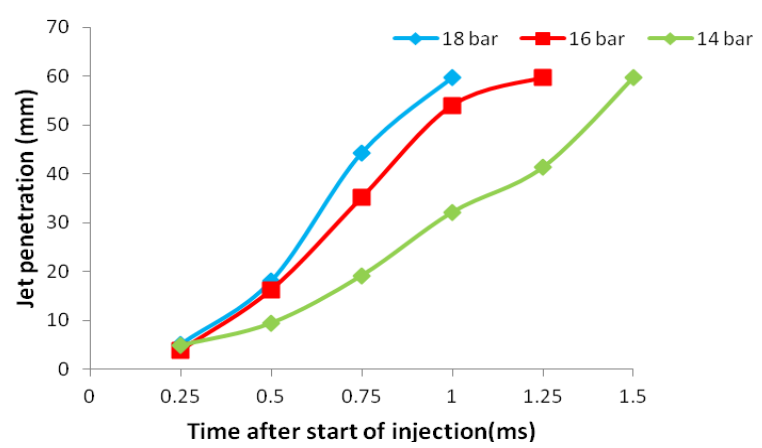

Fig. 5. The effect of injection pressure on the $\mathrm{CNG}$ jet tip penetration at injection pressures: 18, 16 and 14 bar, and injector wall distance: $80 \mathrm{~mm}$.

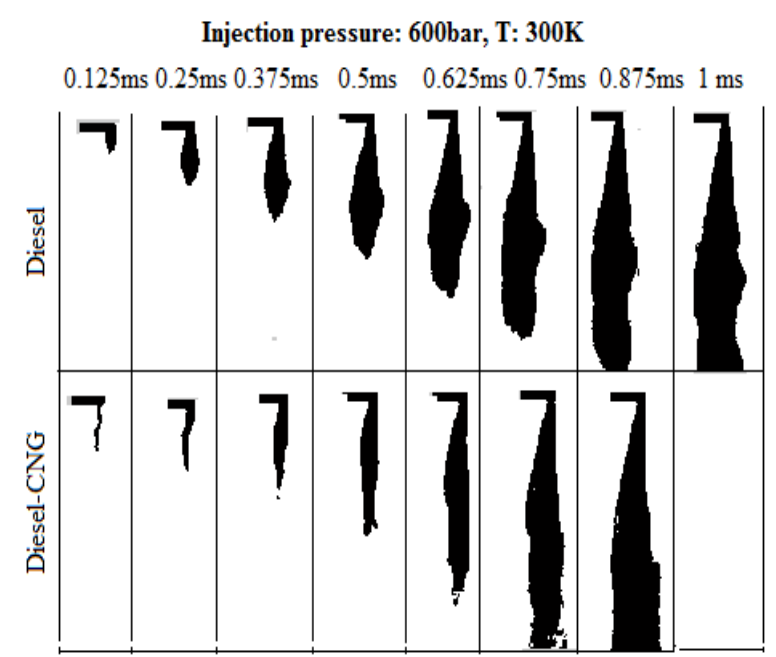

Fig. 6. Schlieren images for diesel and diesel-CNG dual fuel at injection pressure: 600, 18 bar for diesel and CNG respectively and the injector wall distance: $80 \mathrm{~mm}$.

\section{E. Spray Tip Penetration Measurement}

The spray tip penetrations under different temperatures $(300,400$ and $500 \mathrm{~K})$ are presented in Fig. 5 for both diesel and diesel-CNG dual fuel. The rate of spray tip penetration was reduced in both cases as the ambient temperature increased which was in agreement with the findings of Taşkiran and Ergenman [25]. This was caused by the loss of momentum of the jet due to the liquid evaporation. The temperature effect on the diesel spray tip penetration was relatively more significant than that on the diesel-CNG dual-fuel jets as a result of the higher evaporation rate of the diesel jet in the absence of the CNG. Furthermore, it can be seen that, in the case of diesel spray (single fuel), the profiles for both charge-temperature $(400 \mathrm{~K}$ and $500 \mathrm{~K})$ diverged after $0.5 \mathrm{~ms}$ from the start of injection. The rate of diversion increased as the temperature increased. While in the case of dual fuel, the effect of charge temperature on the spray rate of penetration was not as significant. This is due to the 
temperature gradient in the direction of the jet penetration having a greater effect in the absence of CNG. This was due to the fact that the effect of temperature became lower as the mass quantity (diesel+ CNG) increased. The findings of this work on penetration rate (liquid phase under evaporation) with time agree with both Kennaird et al. [17] and Sazhin et al. [16] who found that the penetration was linear with time. The main reasons for the vapour jet transport was the losses of the momentum of the jet by the surrounding air motion as suggested by [25], [26].

To go further in the comparison between sprays of single diesel fuel and diesel-CNG dual fuel, the diesel injection pressure was changed to 500,600 and 700 bar at $500 \mathrm{~K}$ temperature as depicted in Fig. 7.

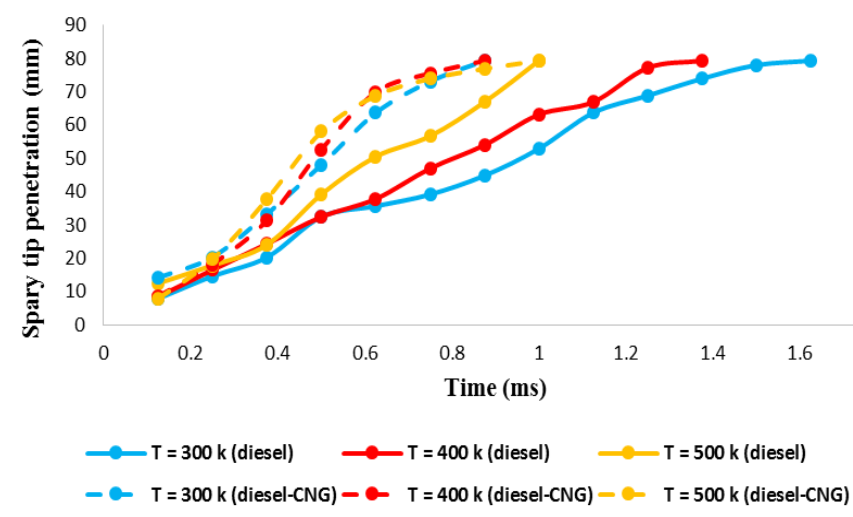

Fig. 7. Effect of different temperatures (500, 400 and $300 \mathrm{~K}$ ) on the diesel and diesel-CNG dual fuel at injection pressure: 600 and 18 bar for diesel and CNG respectively.

As expected, the results showed that the highest rate of penetration was found to occur with the highest injection pressures. The results also showed that the diesel spray (single fuel) started to diverge earlier than that of the diesel-CNG dual-fuel. This was probably caused by the effect of the CNG jet velocity in the axial direction which was higher than the effect of the temperature profiles. Also it can be noticed that the differences in the tip penetration between injection pressure 500, 600 and 700 bar in diesel spray (single fuel) were greater in comparison with the differences between same pressures in the diesel-CNG dual fuel case. Based on this trend, the main reason was probably again related to both quantity and the axial velocity of the diesel spray influenced by the relative velocity of the CNG jet more than that of ambient air as in single diesel spray, Hence, the droplet penetrated faster. This mechanism was studied by Martinez and Benkenida [27] who observed that the droplets velocities gradually approached that of the carrier phase. They suggested that, in evaporating sprays, the characteristics time of evaporation is so small compared to the follow through time. Furthermore, the effects of profile temperature on the droplets in both cases are greater at low injection pressure. This can be reasoned by the diesel spray being less dense at high injection pressures [28], in addition, the higher injection pressures generate small droplets and increase the rate of fuel delivery time, hence, resulted in a reduction in the rate of evaporation and heat transfer.

\section{F. Calculations of the Diesel Jet Characteristics}

The calculation of the diesel spray tip penetration developed by Hiroyasu and Arai [19] are given in Eq. (2) and (3), and the comparison with the experimental results are shown in Fig. 8. Assuming a constant spray tip penetration is not a good representation for spray tip penetration with time. Instead of this, a rapid increase up to maximum value, which is equal break-up time represented by $t_{\text {break }}$, as observed in the experiment (Fig. 8).

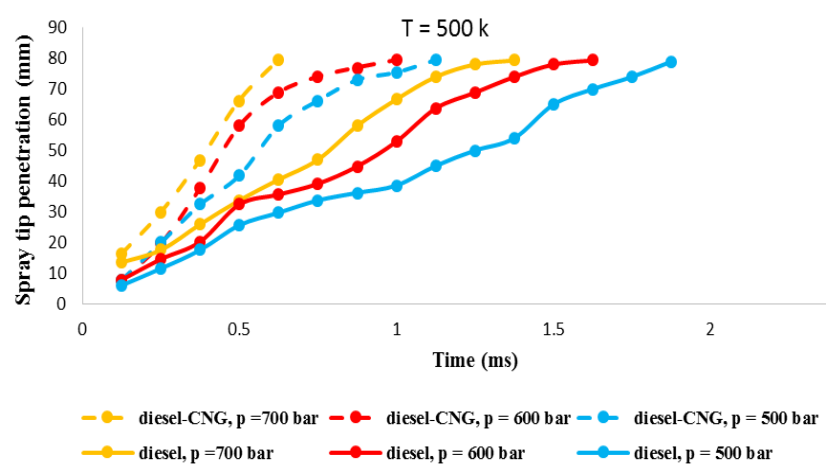

Fig. 8. Effect of different injection pressures $(500,600$ and 700 bar) on the diesel and diesel-CNG dual fuel at $500 \mathrm{~K}$ wall temperatures.

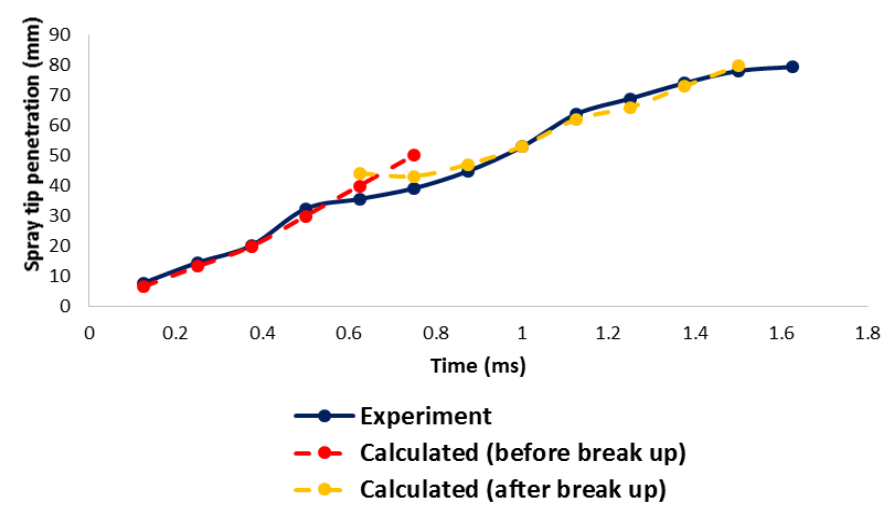

Fig. 9. Comparison between experimental and calculated spray tip penetration of diesel fuel at injection pressure 600 bar and ambient temperature $300 \mathrm{~K}$.

While Dent's [20] equation based on the gas jets theory, where spray penetration depends on the gas density and temperature is given in Eq. (5) This equation is applicable only for $\mathrm{t}>0.5 \mathrm{~ms}$. Therefore, there is no agreement between the experiment and the calculated jet tip penetration after this range as shown in Fig. 8.

\section{G. Effects of Wall Impingement on the Diesel-CNG Dual Fuel Jet Development}

Fig. 11 shows the comparison between the development of the CNG jet and the diesel spray on the wall. It can be seen that the CNG jet was largely affected by the ambient air due to its low density and momentum.

The development of the diesel and diesel-CNG dual fuel jet on the radial penetration along the wall and the jet height are presented in Fig. 9. The injection pressures of diesel and CNG were 600 bar and 18 bar respectively at ambient wall temperature of $300 \mathrm{~K}$. It can be seen that the diesel-CNG dual fuel had a higher radial penetration than that of pure diesel. This phenomenon can be reasoned as following: as the pure diesel spray approaches the wall, it losses axial velocity caused by the interaction between the liquid and the wall, while in incase of diesel-CNG dual fuel, the axial velocity 
was enhanced by the $\mathrm{CNG}$ jet resulting in a higher radial penetration on the wall. On the other hand, for the jet height, the pure diesel spray showed higher height than that of diesel-CNG dual fuel. This was probably due to the CNG jet having a lower density and thus easily mixed with ambient air while the diesel focused on the wall. The findings of this work are consistent with other results sets reported in literature [29].

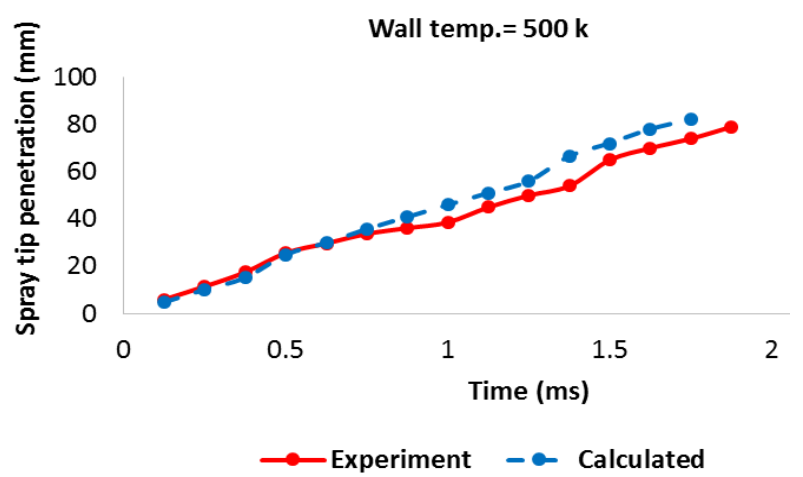

Fig. 10. Comparison between experimental and calculated spray tip penetration of the diesel fuel at injection pressure 600 bar and the wall temperature $500 \mathrm{~K}$.

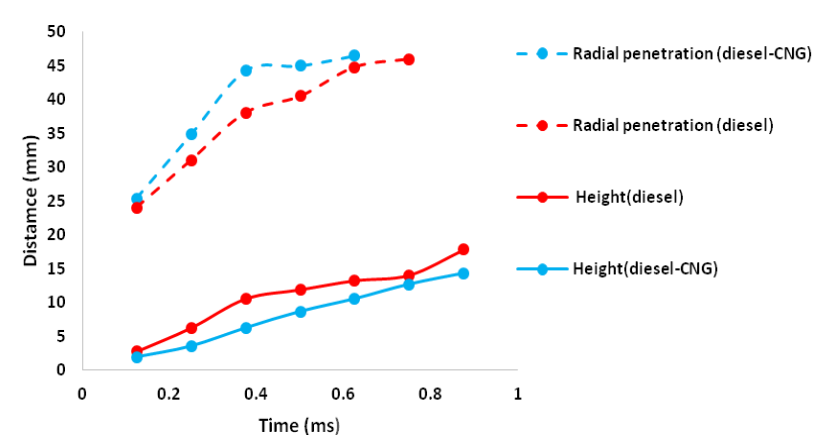

Fig. 11. The radial penetration and height of diesel and diesel-CNG dual fuel jet impinged on the wall (inj. $\mathrm{P}=600 \mathrm{bar}$ for diesel and 18 bar for $\mathrm{CNG}$ and injector the wall distance: $60 \mathrm{~mm}$ and the wall temperature $300 \mathrm{~K}$ ).

\section{CONCLUSIONS}

Two types of injectors have been used to characterize the propagations of CNG jets and Diesel-CNG dual-fuel jets namely a CNG electronic injector and a high pressure common rail diesel injector. Finally, the following conclusions were obtained based on the investigation.

1) The $\mathrm{CNG}$ jet penetration rate was found to be largely affected by the ambient pressure at the beginning of injection for low injection pressure and short injector-wall distance. The CNG jet travel along the wall in both radial and height directions were found to be significantly affected by injection and ambient pressure.

2) The penetration rate of the diesel spray was largely influenced by the $\mathrm{CNG}$ jet in the axial direction rather than the radial direction. The effect resulted in higher penetration rate with lower jet cone angle than that of the pure diesel spray.

3) The effect of diesel injection pressure on the dual fuel injection was not as significant as compared to the pure diesel spray. The penetration rate of diesel-CNG dual-fuel jet was influenced slightly by the ambient temperature as compared to the pure diesel spray. On the other hands, the spray cone angles of the single and dual-fuel did not show significant differences.

4) For the jet wall-impingement, the diesel-CNG dual-fuel was observed to be higher penetration as compared to pure diesel fuel. On the other hands, the diesel spray was observed to be largely affected by the wall temperature in comparison to the diesel-CNG dual fuel.

\section{ACKNOWLEDGMENT}

The authors would like to acknowledge the support given by Universiti Teknologi PETRONAS to the Centre for Automotive Research and Electric Mobility in performing this research and the University of Bahri to Mechanical Engineering Department.

\section{REFERENCES}

[1] S. Schneider, "The greenhouse effect- Science and policy," Science, pp. 1-21, 1989.

[2] T. Korakianitis, M. Namasivayam, and R. J. Crookes, "Natural-gas fueled spark-ignition (SI) and compression-ignition (CI) engine performance and emissions," Progress in Energy and Combustion Science, vol. 37, no. 1, pp. 89-112, Feb. 2011.

[3] J. Stewart, A. Clarke, and R. Chen, "An experimental study of the dual-fuel performance of a small compression ignition diesel engine operating with three gaseous fuels," The Institution of Mechanical Engineers, Journal of Automobile Engineering, vol. 221, no. 8, pp. 943-956, Jan. 2007.

[4] J. Harrington, S. Munshi, C. Nedelcu, P. Ouellette et al., "Direct injection of natural gas in a heavy-duty diesel engine," SAE Technical Paper 2002-01-1630, 2002.

[5] C. Engines and N. J. Birger, "Flow characteristics of gas-blast fuel injectors for direct-injection," The University of British Columbia, April, 2010.

[6] H. J. Kim, S. H. Park, and C. S. Lee, "A study on the macroscopic spray behavior and atomization characteristics of biodiesel and dimethyl ether sprays under increased ambient pressure," Fuel Processing Technology, vol. 91, no. 3, pp. 354-363, Mar. 2010.

[7] T. H. E. Republic and O. F. Korea, "A basic study of the behavior characteristics of gas- and liquid- phase fuel spray," Recent Advances In Fluid Mechanics, pp. 80-85, 2007.

[8] Y. M. Arifin and M. Arai, "The effect of hot surface temperature on diesel fuel deposit formation," Fuel, vol. 89, no. 5, pp. 934-942, May 2010.

[9] P.-C. Chen, W.-C. Wang, W. L. Roberts, and T. Fang, "Spray and atomization of diesel fuel and its alternatives from a single-hole injector using a common rail fuel injection system," Fuel, Aug. 2012.

[10] J. Yu, H. Hillamo, T. Sarjovaara, T. Hulkkonen, O. Kaario, and M Larmi. Experimental investigation on low pressure gas jet characteristics by tracer-based PLIF technique. [Online]. pp. 1-14. Available: http://www.ffrc.fi/FlameDays_2011/Session_2_Engines/18yu.pdf

[11] J. Yu, H. Hillamo, V. Vuorinen, T. Sarjovaara, O. Kaario, and M. Larmi, "Experimental investigation of characteristics of transient low pressure wall-impinging gas jet," Journal of Physics: Conference Series, vol. 318, no. 3, pp. 32-47, Dec. 2011.

[12] A. Matsumoto, W. R. Moore, M. Foster, D. Yen, K. Confer, and E. Hopkins, "Spray characterization of ethanol gasoline blends and comparison to a CFD model for a gasoline direct injector," Fuel, 2010.

[13] T. I. Mohamad and H. H. Geok, "PLIF Flow Visualization of Methane Gas Jet from Spark Plug Fuel Injector in a Direct Injection Spark Ignition Engine," in Proc. the 1st WSEAS International Conference on Visualization, Imaging and Simulation, 2008, pp. 35-40.

[14] T. Senoo, M. Sasaki, and M. Shioji, "Spark-igntion stability of natural-gas jets with impingement on cavity walls spark-IG ITIO stability of atural-gas jets with," Most, 2010.

[15] R. J. H. K. Douwel, P. J. M. Frijters, L. M. T. Somers, W. Boer, and R. S. G. Baert, "Macroscopic diesel fuel spray shadowgraphy using high speed digital imaging in a high pressure cell," Fuel, vol. 86, no. 12-13, pp. 1994-2007, Aug. 2007.

[16] S. Sazhin, W. Abdelghaffar, E. Sazhina, and M. Heikal, "Models for droplet transient heating: Effects on droplet evaporation, ignition, and 
break-up," International Journal of Thermal Sciences, vol. 44, no. 7, pp. 610-622, Jul. 2005.

[17] D. A. Kennaird, C. Crua, J. Lacoste, M. R. Heikal, M. R. Gold, and N. S. Jackson, "In-cylinder penetration and break-up of diesel sprays using a common-rail injection system," Silniki Spalinowe, 2002.

[18] R. Lillington, "A Review of Heavy Duty Diesel Injector Characterization," Journal of Aerosol Science, pp. 1-19, 2011.

[19] H. Hiroyasu and M. Arai, "Structures of fuel sprays in diesel engines," SAE Paper No. 900475, 1990.

[20] C. Dent, "A basis for the comparison of various experimental methods for studying spray penetration," SAE Paper No. 710571, 1971.

[21] Hiroyasu, "Diesel engine combustion and its modeling," in Proc. the International Symposium on Diagnostics and Modeling of Combustion in Reciprogating Engines, 1985, pp. 53-75.

[22] N. Studies and T. Karimipanah, "Thesis submitted for the degree of doctor of philosophy in the centre for built environment," Royal Institute of Technology, Gävle Sweden, 1996.

[23] S. Mohammed and E. Iffa, "Spray characteristic comparisons of compressed natural gas and hydrogen fuel using digital imaging," Journal of Applied, pp. 1-5, 2010.

[24] Semin, "Injector nozzle spray on compressed natural gas engines: A technical review," International Review of Mechanical Engineerin, vol. 6, no. 5, p. 5013, 2012.

[25] Ö. O. Taşkiran and M. Ergeneman, "Experimental study on diesel spray characteristics and autoignition process," Journal of Combustion, vol. 2011, pp. 1-20, 2011

[26] A. Magnusson and S. Andersson, "An experimental study of heat transfer between impinging single diesel droplets and a metal wall using a surface mounted height adjustable rapid thermocouple," in Proc. the $24^{\text {th }}$ European Conference on Liquid Atomization and Spray Systems, September, 2011, pp. 1-7.

[27] J. Lacoste, "Characteristics of diesel sprays at high temperatures and pressures," Research, 2006.

[28] S. W. Park and C. S. Lee, "Macroscopic and microscopic characteristics of a fuel spray impinged on the wall," Experiments in Fluids, vol. 37, no. 5, pp. 745-762, Sep. 2004.

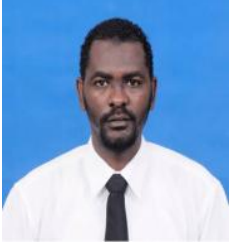

Mhadi A. Ismael received the master science in mechanical engineering, Automotive Department, Universiti Teknologi Petronas, Malaysia. He received his bachelor of science degree in mechanical engineering, University of Juba, Khartoum, Sudan.

He works as the head of mechanical engineering Department, University of Bahri. His recent research concentrates on the IC engines, Schlieren techniques, and Spray Characteristics.

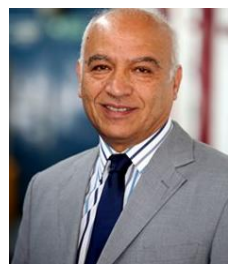

Morgan Heikal is a senior professor at automotive research and electric mobility, Mechanical Department, Universiti Teknologi Petronas, Malaysia $\mathrm{He}$ also works as the head of the Centre for Automotive Engineering, Ricardo is a professor of automotive engineering, the head of engineering in a research centre etc. His recent research concentrates on IC engines, laser diagnostic techniques and compact heat exchangers.

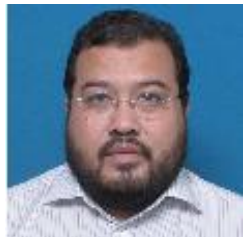

Masri Bin Baharom is an associate professor of mechanical engineering at the University Teknologi Petronas. He received his $\mathrm{PhD}$ (vehicle dynamics), University of Bradford, UK. He got his master science degree in automotive engineering, University of Leeds. And he received bachelor of science degree in mechanical engineering, University of Rochester, USA. He is interested in the automotive -vehicle and chassis design, vehicle dynamics, vehicle control engine - novel engine design, engine testing, combustion analysis, alternative fuels, etc. 